\title{
Genetic Relationships among 10 Prunus Rootstock Species from China, Based on Simple Sequence Repeat Markers
}

\author{
Qijing Zhang and Dajun Gu' \\ Liaoning Institute of Pomology, Yingkou, Liaoning 115009, People's Republic of China
}

\begin{abstract}
AdDitional INDEX wORDs. microsatellite markers, banding patterns, phylogenetic analysis, subgenus classification, rootstock breeding

Abstract. To improve the efficiency of breeding programs for Prunus rootstock hybrids in China, we analyzed the subgenus status and relationship of 10 Chinese rootstock species, by using 24 sets of simple sequence repeat (SSR) primers. The SSR banding patterns and phylogenetic analysis indicated that subgenus Cerasus is more closely related to subgenus Prunophora than to subgenus Amygdalus, and that subgenus Lithocerasus is more closely related to subgenus Prunophora and subgenus Amygdalus than to subgenus Cerasus. In addition, Prunus triloba was more closely related to Prunus tomentosa than to the members of subgenus Amygdalus. Therefore, we suggest that $P$. tomentosa and $P$. triloba should be assigned to the same group, either to subgenus Lithocerasus or Prunophora, and we also propose potential parent combinations for future Prunus rootstock breeding.
\end{abstract}

Prunus (Rosaceae) is a large genus with significant economic importance, since it includes a variety of popular stone fruit species [e.g., peach (Prunus persica), apricot (Prunus armeniaca), almond (Prunus dulcis), and sweet cherry (Prunus avium)]. The genus comprises a polyploid series, of which the basic chromosome number is $x=8$, and is characterized morphologically by flowers with five sepals, five petals, and a solitary carpel with a terminal style; fruit that are fleshy drupes; and branches with solid pith (Rehder, 1990). Many Prunus species are also important as sources of rootstocks. Furthermore, the genetic resources within the genus are abundant, since the genus comprises $\approx 200$ species, and $\approx 100$ Prunus species are indigenous to China (Yü and $\mathrm{Li}, 1986$ ). However, the classification of Prunus species is sometimes controversial, partly owing to the ease of interspecific hybridization (Dosba et al., 1994), which results in the frequent occurrence of intermediate morphotypes. Previously, Rehder (1990) divided Prunus into five subgenera: Prunophora (plum and apricot), Amygdalus (peach, nectarine, and almond), Cerasus (cherry), Padus (cluster cherry), and Laurocerasus (laurel cherry), and later, Ingram (1948) added a sixth subgenus, Lithocerasus, by splitting the bush cherry and rock cherry.

Species that originated in China include $P$. tomentosa, $P$. triloba, Prunus japonica, Prunus glandulosa, and Prunus humilis, which are among the important dwarf rootstock species used for peach, plum, and apricot (Ding, 1997). Of these species, $P$. tomentosa has been cultivated for fruit production in China for over 2000 years, owing to its cold resistance and good fruiting habit (Yü and Li, 1986), and P. humilis has been gradually increasing in popularity as a promising Chinese fruit tree, owing to the high calcium content of its fruit. Meanwhile, Prunus pseudocerasus and Prunus serrulata (subgenus Cerasus) have long been used as rootstocks for sweet cherry, ever since sweet cherry was introduced to China, and Prunus davidiana can be used as a rootstock for plum, apricot, and

Received for publication 20 May 2016. Accepted for publication 22 July 2016. ${ }^{1}$ Corresponding author. E-mail: dajungu@163.com. peach, whereas Prunus salicina and Prunus sibirica can be used as a rootstock for cherry, plum, apricot, and peach. Hybridization among Prunus species has been successful and has been taken up as an effective strategy for improving rootstock cultivars (Felipe, 2009; Jones, 1928; Shoferistov, 1989; Zhang and Gu, 2015). However, using such a strategy to improve the efficiency of breeding programs requires a sufficient understanding of the groups' phylogeny and of the degree of homology between the genomes of different species.

Therefore, the analysis of genetic relationships among Prunus species can provide basic information for broadening the genetic basis of rootstock breeding programs. Molecular systematic analyses have been performed on Prunus rootstock species using isozymes (Mowrey and Werner, 1990), restriction-fragment length polymorphisms [RFLPs (Uematsu et al., 1991)], random amplified polymorphic DNA [RAPD (Shimada et al., 2001)], internal transcribed spacer (ITS) sequences (Sangtae and Wen, 2001), and the combination of nuclear ribosomal ITS and plastid markers (Chin et al., 2014). In addition, genomic SSR markers have also been used for genotyping, germplasm characterization, and fingerprinting in many plant species, since they are polymerase chain reaction (PCR)based, highly polymorphic, codominant, abundant, and highly reproducible (Powell et al., 1996), and moreover, genomic SSR markers have been developed in almost every cultivated Prunus species. However, previous studies of rootstock species from China have not used these SSR markers. Accordingly, in the present study, we aimed to determine the relationships and genetic diversity of 17 Prunus species and two hybrids using SSR analysis, with particular emphasis on the genetic relationships of 10 rootstock species that originated in China.

\section{Materials and Methods}

Plant materials. We sampled 40 accessions from the Xiongyue Arboretum (Yingkou, China) of which five accessions 
(three species) belonged to subgenus Prunophora, five accessions (three species) to subgenus Amygdalus, eight accessions (four species) to subgenus Lithocerasus, and 22 accessions (seven species and two hybrids) to subgenus Cerasus (Table 1).

Genomic DNA extraction. Total genomic DNA was extracted from young expanded terminal leaves using the citrimonium bromide method (Doyle and Doyle, 1990) with minor modifications. Then, the concentration and quality of the DNA were assessed using ultraviolet-visible spectrophotometry (DU 800; Beckman Coulter, Fullerton, CA) and electrophoresis on $1 \%$ TAE agarose gels, and the samples were diluted to a final concentration of $250 \mathrm{ng} \cdot \mu \mathrm{L}^{-1}$.

Table 1. Forty Prunus accessions used in genetic relationship analysis among 10 rootstock species from China by simple sequence repeat.

\begin{tabular}{|c|c|c|c|c|c|}
\hline Code & Accession & Type & Species & Subgenus & Origin \\
\hline 1 & Bing & Cherry & Prunus avium & Cerasus & America \\
\hline 2 & Hongdeng & Cherry & P. avium & Cerasus & China \\
\hline 3 & Lapins & Cherry & P. avium & Cerasus & Canada \\
\hline 4 & Early Ruby & Cherry & P. avium & Cerasus & Russia \\
\hline 5 & Gisela 5 & Cherry & $\begin{array}{l}\text { Prunus cerasus } \times \\
\quad \text { Prunus canescens }\end{array}$ & Cerasus & German \\
\hline 6 & Colt & Cherry & $\begin{array}{l}\text { P. avium } \times \text { Prunus } \\
\text { pseudocerasus }\end{array}$ & Cerasus & UK \\
\hline 7 & Xinxing & Cherry & Prunus fruticosa & Cerasus & Russia \\
\hline 8 & Askaya & Cherry & P. fruticosa & Cerasus & Russia \\
\hline 9 & Xiwang & Cherry & P. fruticosa & Cerasus & Russia \\
\hline 10 & Early Richmond & Cherry & P. cerasus & Cerasus & Unknown \\
\hline 11 & Shuanyingtao A & Cherry & P. cerasus & Cerasus & Unknown \\
\hline 12 & Shuanyingtao B & Cherry & P. cerasus & Cerasus & Unknown \\
\hline $13^{z}$ & Daqingye & Cherry & P. pseudocerasus & Cerasus & China \\
\hline $14^{z}$ & Xiaoqingye & Cherry & P. pseudocerasus & Cerasus & China \\
\hline $15^{z}$ & Laiyangaiying & Cherry & P. pseudocerasus & Cerasus & China \\
\hline $16^{\mathrm{z}}$ & Dawolouye & Cherry & P. pseudocerasus & Cerasus & China \\
\hline $17^{\mathrm{z}}$ & Shanying A & Cherry & Prunus serrulata & Cerasus & China \\
\hline $18^{z}$ & Shanying B & Cherry & P. serrulata & Cerasus & China \\
\hline $19^{\mathrm{z}}$ & Shanying C & Cherry & P. serrulata & Cerasus & China \\
\hline $20^{z}$ & Shanying D & Cherry & P. serrulata & Cerasus & China \\
\hline 21 & Mahaleb & Cherry & Prunus mahaleb & Cerasus & Unknown \\
\hline $22^{z}$ & Maoyingtao A & Cherry & Prunus tomentosa & Lithocerasus & China \\
\hline $23^{z}$ & Maoyingtao B & Cherry & P. tomentosa & Lithocerasus & China \\
\hline $24^{z}$ & $\begin{array}{c}\text { Maoyingtao C } \\
\text { (whipping) }\end{array}$ & Cherry & P. tomentosa & Lithocerasus & China \\
\hline $25^{z}$ & Yuyemei A & Almond & Prunus triloba & Amygdalus & China \\
\hline $26^{\mathrm{z}}$ & Yuyemei B & Almond & P.triloba & Amygdalus & China \\
\hline $27^{z}$ & Yuyemei C & Almond & P. triloba & Amygdalus & China \\
\hline $28^{z}$ & Fuli & Plum & Prunus salicina & Prunophora & China \\
\hline 29 & Gaixiandali & Plum & P. salicina & Prunophora & China \\
\hline $30^{z}$ & Xiaohuangli & Plum & P. salicina & Prunophora & China \\
\hline $31^{z}$ & Gaiguo 3 & Cherry & Prunus humilis & Lithocerasus & China \\
\hline $32^{z}$ & Gaiguo 4 & Cherry & P. humilis & Lithocerasus & China \\
\hline $33^{z}$ & Yuli & Cherry & Prunus japonica & Lithocerasus & China \\
\hline $34^{z}$ & Mailiwhite & Cherry & Prunus glandulosa & Lithocerasus & China \\
\hline $35^{z}$ & MailiRed & Cherry & P. glandulosa & Lithocerasus & China \\
\hline 36 & Yinghua & Cherry & Prunus yedoensis & Cerasus & Japan \\
\hline $37^{z}$ & Shantao & Peach & Prunus davidiana & Amygdalus & China \\
\hline 38 & Chongyanghong & Peach & Prunus persica & Amygdalus & China \\
\hline 39 & Katy & Apricot & Prunus armeniaca & Prunophora & America \\
\hline $40^{\mathrm{z}}$ & Shanxing & Apricot & Prunus sibirica & Prunophora & China \\
\hline
\end{tabular}

${ }^{\mathrm{z}}$ Prunus rootstock species that originated in China.
PCR AMPLIFICATION AND PRODUCT ELECTROPHORESIS. The diluted genomic DNA was PCR amplified using 24 sets of SSR primers that were previously developed in peach, apricot, and cherry (Table 2 ). The $20-\mu \mathrm{L}$ reaction mixture contained $20 \mathrm{~mm}$ Tris- $\mathrm{HCl}(\mathrm{pH} 8.4), 50 \mathrm{~mm} \mathrm{KCl}, 4 \mathrm{~mm} \mathrm{MgCl}_{2}, 0.1 \mathrm{~mm}$ each $\mathrm{dNTP}, 0.2 \mathrm{M}$ each primer, $40 \mathrm{ng}$ genomic DNA, and $0.45 \mathrm{U}$ Taq polymerase and were amplified using a thermocycler (PTC200; MJ Research, Waltham, MA) with the following program: an initial denaturation of $4 \mathrm{~min}$ at $94^{\circ} \mathrm{C} ; 28-31$ cycles of $45 \mathrm{~s}$ at $94{ }^{\circ} \mathrm{C}, 45 \mathrm{~s}$ at $57.5-62{ }^{\circ} \mathrm{C}$, and $45 \mathrm{~s}$ at $72{ }^{\circ} \mathrm{C}$; and a final extension of $8 \mathrm{~min}$ at $72{ }^{\circ} \mathrm{C}$. The amplification products were electrophoresed on $8 \%$ polyacrylamide gels in $1 \times$ TBE buffer with a constant current of $40 \mathrm{~mA}$, and the gels were stained with silver nitrate (Promega, Madison, WI), according to the manufacturer's instructions. In addition, amplification with each primer combination was performed twice to verify the reproducibility of our results.

SSR DATA ANALYSIS. Each SSR band was considered an individual character, and the presence or absence of the band was scored using binary code (present $=1$, absent $=$ 0 ). Subsequently, a data matrix was assembled and analyzed using PAUP* (Swofford, 1998), and a pairwise distance matrix was generated based on total character differences. The genetic relatedness of the Prunus species was analyzed using the unweighted pair group method with arithmetic mean (UPGMA), based on total character difference, and bootstrap analysis was conducted using UPGMA search methods with 10,000 replicates, to obtain confidence values for the branches of the tree.

\section{Results and Discussion}

SSR MARKER CHARACTERIZATION. Bands or banding patterns that are unique to specific groups can be used for species identification or subgenus classification (Zhang et al., 2008). To identify the more common alleles shared by different species, 24 SSR primer sets were selected from over 170 pairs of primers that were previously developed for peach, cherry, and apricot (Zhang et al., 2008). In the present study, a total of 251 alleles were identified, with a mean of 10.5 alleles per SSR locus. Among the 24 loci, the CPPCT27 locus was the most polymorphic, with 17 alleles, whereas the UCD-CH12 locus was the least polymorphic, with only six alleles (Table 2). 
Table 2. List of simple sequence repeat primers used in genetic relationship analysis and their amplified products in 40 Prunus accessions.

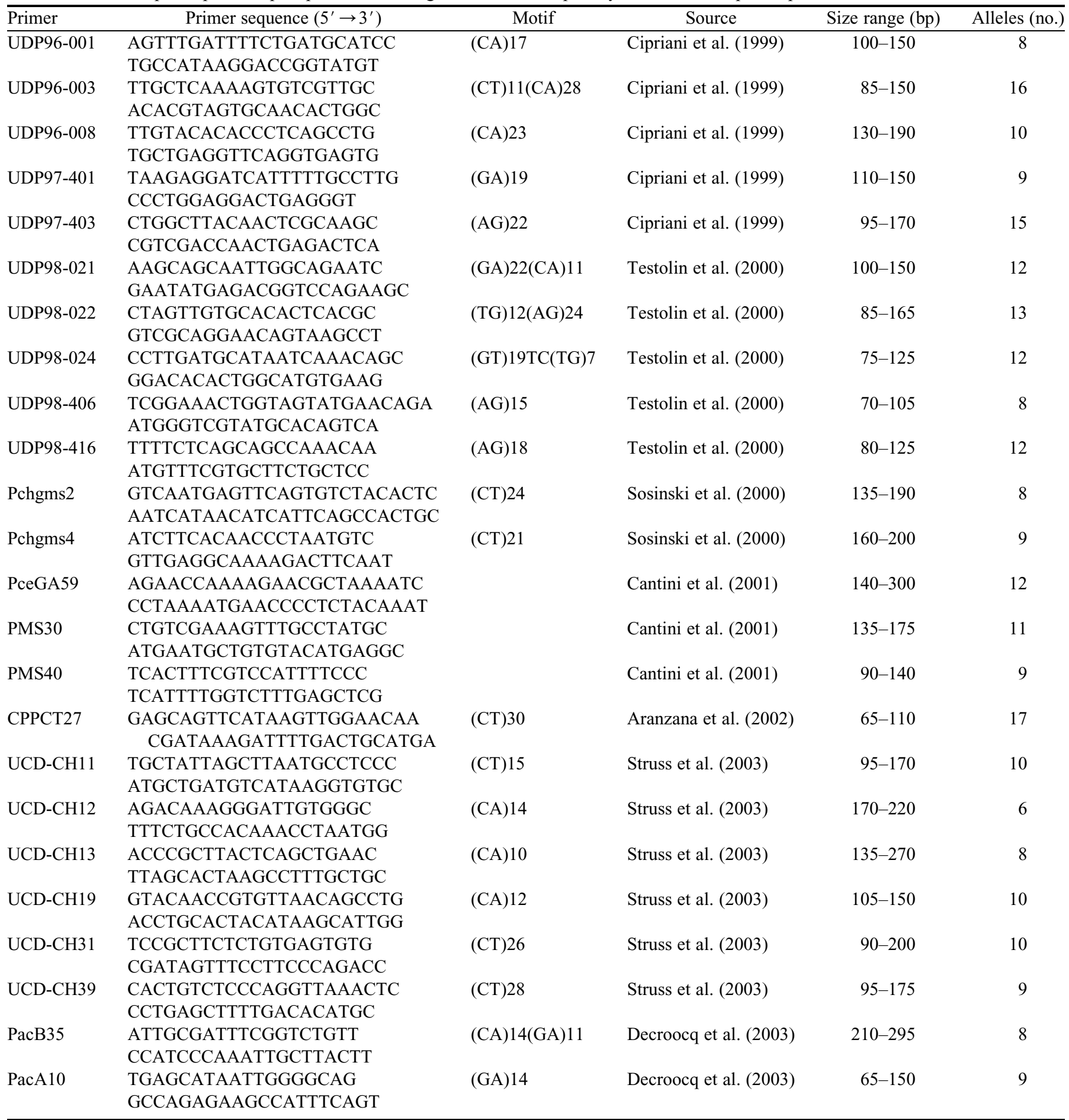

Both common and unique alleles were identified using 10 group-specific markers on a certain set of species (Table 3 ).

For example, one allele at the UDP96-003 locus was shared by accessions of $P$. tomentosa, $P$. humilis, $P$. japonica, and $P$. glandulosa and, therefore, was able to distinguish species in subgenus Lithocerasus from those in the other subgenera, whereas another allele from the same locus was shared by P. triloba and P. salicina (Fig. 1A). Similarly, the PacA10 locus was able to distinguish $P$. salicina (subgenus Prunophora) from $P$. tomentosa, $P$. triloba, $P$. humilis, $P$. japonica, $P$. glandulosa (subgenus Lithocerasus), $P$. davidiana, and $P$. persica [subgenus Amygdalus (Fig. 1B)]; and the UCD-CH31 and UCD-CH39 loci were able to distinguish $P$. tomentosa from all other species. In addition, both the UDP96-008 and UDP97-401 loci yielded species-specific alleles for each of $P$. japonica, $P$. humilis, and $P$. glandulosa; and the UDP96-008, UDP98-024, and CPPCT27 loci yielded a common allele for $P$. davidiana and $P$. persica (subgenus Amygdalus) (Table 3).

In addition, we also found that subgenus Cerasus ( $P$. avium, Prunus fruticosa, Prunus cerasus, P. pseudocerasus, P. serrulata, 
Table 3. Ten group-specific simple sequence repeat markers applied to genetic relationship analysis among 40 Prunus accessions distinguish a set of species by generating common and unique bands.

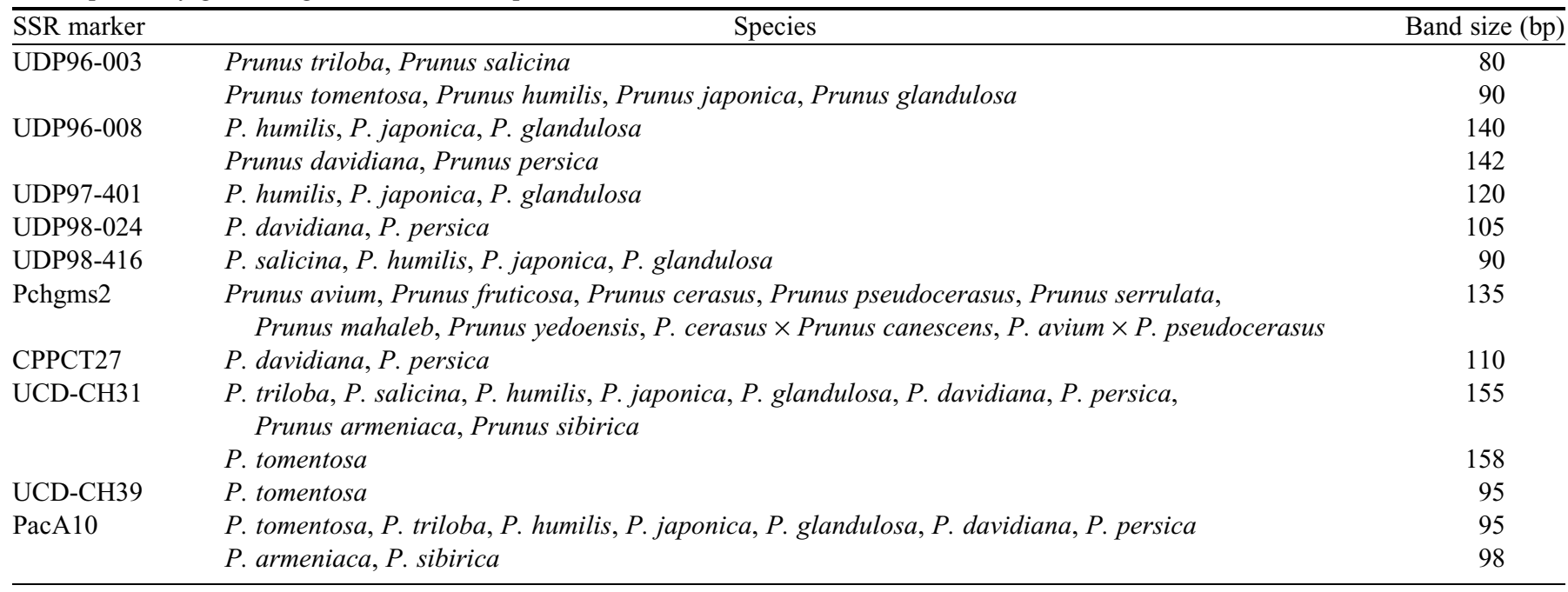
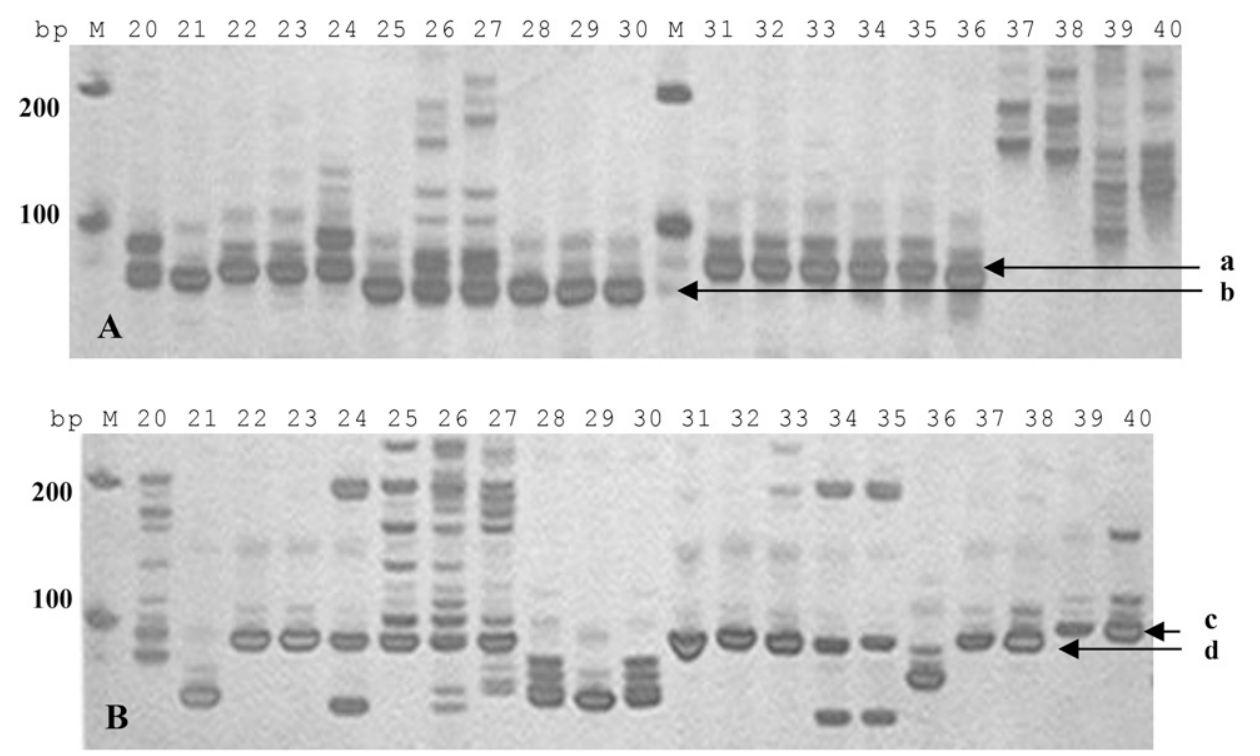

Fig. 1. Simple sequence repeat band patterns of 21 Prunus accessions generated by UDP96-003 and PacA10 markers. (A) Marker UDP96-003: allele "a" was shared by Prunus tomentosa, Prunus humilis, Prunus japonica, and Prunus glandulosa; allele "b" was shared by Prunus triloba and Prunus salicina. (B) Marker PacA10: allele "c" was shared by Prunus armeniaca and Prunus sibirica; allele "d" was shared by $P$. tomentosa, P. triloba, P. humilis, P. japonica, P. glandulosa, Prunus davidiana, and Prunus persica. Prunus accession numbers are detailed in Table $1 ; \mathrm{M}=$ DNA size markers.

Prunus mahaleb, Prunus yedoensis, P. cerasus $\times$ Prunus canescens, and $P$. avium $\times$ P. pseudocerasus) could be distinguished by a unique allele at the Pchgms2 locus. Although subgenus Cerasus exhibits a wide geographic distribution, all the specimens included in the present study possessed the same allele, whereas the other species exhibited polymorphism. During the optimization of Pchgms2 amplification, only a single allele was amplified under different annealing temperatures $(52,55,58$, and $60^{\circ} \mathrm{C}$ ) in the 22 accessions representing subgenus Cerasus. Thus, the locus Pchgms2 was very useful for identifying subgenus Cerasus.

Among the 24 loci, the UCD-CH12 locus was determined to be the most suitable for homology analysis, with four common alleles shared by the 17 species and 2 hybrids analyzed, and could be useful for elucidating relationships within the genus. Thus, it might eventually be possible to classify Prunus species using only one or two SSR markers. Cipriani et al. (1999) reported that $59 \%$ of peach SSR primer pairs amplified products of expected size in other Prunus species. Our results also show that the examined Prunus species were closely related and that SSR primer pairs exhibit high transferability within the genus. Although Dirlewanger et al. (2002) reported that the transferability of primer pairs across species is not related to genetic distance, our results indicated that more closely related species were more likely to share similar alleles. For example, $P$. humilis, $P$. japonica, and $P$. glandulosa shared a distinguishing allele with $P$. salicina at locus UDP98-416; and P. humilis, $P$. japonica, P. glandulosa, P. triloba, and $P$. tomentosa shared a distinguishing allele with $P$. davidiana and P. persica at locus PacA10 (Table 3), which indicated that subgenus Lithocerasus was more closely related to subgenus Prunophora than subgenus Cerasus.

Phylogenetic analysis. All the accessions from subgenus Cerasus clustered together (Fig. 2), thus providing support for their common genetic origin. P. cerasus and P. fruticosa were more closely related to each other than to $P$. avium, which supports the hypothesis that $P$. cerasus arose as an allotetraploid from the hybridization of $P$. avium $(2 n=2 x=16)$ and $P$. fruticosa $(2 n=4 x=32$; Olden and Nybom, 1968). Meanwhile, the hybrid 'Gisela 5' (P. cerasus $\times P$. canescens) connected the $P$. avium group to the group that contained $P$. cerasus and $P$. fruticosa, and the hybrid 'Colt' (P. avium $\times$ P. pseudocerasus $)$ was grouped between the cherries from Asia and Europe. 


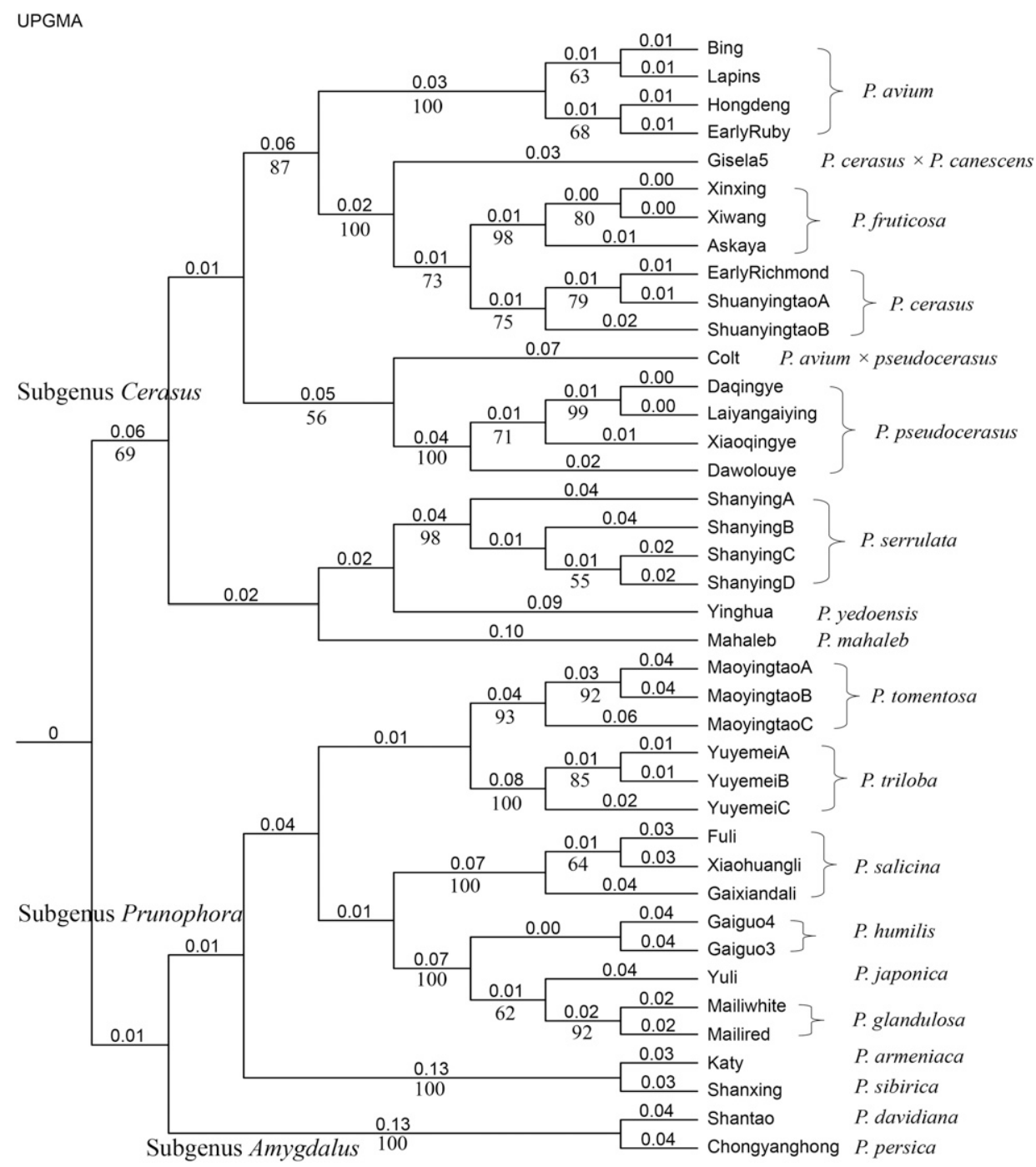

Fig. 2. Dendrogram of 40 Prunus accessions based on unweighted pair group method with arithmetic mean analysis of simple sequence repeat data. Numbers below the lines indicate bootstrap values (percentage of 1000 replicates). Bootstrap values greater than $50 \%$ are shown.

Although $P$. mahaleb originated in Europe, it was closely related to cherries from Asia. Generally, subgenus Cerasus is more divergent from the other groups. Subgenus Cerasus was also more closely related to subgenus Prunophora than to subgenus Amygdalus, which confirms the hypothesis that cherry is genetically more distant from peach than from apricot (Badenes and Parfitt, 1995; Chin et al., 2014; Watkins, 1976). Successful hybridization among Prunus species has been reported [e.g., Prunus amygdalus $\times$ P. persica (Felipe, 2009), Prunus domestica $\times$ P. armeniaca (Jones, 1928), P. davidiana $\times$ Prunus mira (Shoferistov, 1989)], which indicates that hybridization and crossing could occur among plum, apricot, and peach, but not with cherry.

The $P$. salicina accessions formed a group with high bootstrap values, along with a group that included $P$. humilis, $P$. japonica, and P. glandulosa (Fig. 2), which together formed a group with $P$. tomentosa and $P$. triloba. The apricot group ( $P$. armeniaca, $P$. sibirica) was more similar to the plum group ( $P$. salicina) than to the peach group ( $P$. davidiana, $P$. persica). A previous morphological study suggested that the evolution of these species progressed from peach $>$ apricot $>$ plum $>$ cherry (Yü and Li, 1986), which is corroborated by the molecular analysis of the present study.

GENETIC DIVERSITY OF FOUR S PECIES FROM SUBGENU S Lithocerasus. The four species from subgenus Lithocerasus that were included in the present study failed to cluster into a single group and, instead, were grouped with members of the subgenus Prunophora. This grouping suggests that subgenus Lithocerasus is closely related to $P$. salicina. A close relationship was previously reported between $P$. glandulosa and P. japonica, which belong to subgenus Prunophora and subgenus Amygdalus, respectively, based on RAPD analysis (Shimada et al., 2001). The present study grouped $P$. japonica, $P$. glandulosa, and P. humilis, and within this group, $P$. glandulosa was more closely related to $P$. japonica than to $P$. humilis. In addition, a previous isozyme study (Mowrey and Werner, 1990) indicated that $P$. japonica only differed from $P$. glandulosa by one of 110 alleles and, moreover, that $P$. japonica and $P$. glandulosa grouped together in subgenus Cerasus. However, although the present study confirms the genetic similarity of $P$. humilis, $P$. japonica, and $P$. glandulosa, the species were placed in subgenus Prunophora (Fig. 2), in agreement with the ITS sequence analysis of Bortiri et al. (2006), which indicated that $P$. tomentosa and $P$. glandulosa were more closely related to subgenus Prunophora than to subgenus Amygdalus.

Evidence from interspecific crosses also supports the classification of subgenus Lithocerasus as distinct from subgenus Cerasus and suggests that subgenus Lithocerasus is more closely related to subgenus Prunophora. For example, members of subgenus Lithocerasus section Microcerasus have been reported to hybridize readily with members of subgenus Prunophora and, to some extent, with members of subgenus Amygdalus, but generally fail to hybridize with members of subgenus Cerasus (Garley, 1980; Kataoka et al., 1988). Furthermore, $P$. japonica is also capable of growing on rootstocks of both $P$. glandulosa and $P$. armeniaca (Fan, 1999), and the grafting compatibilities between some members of subgenus Lithocerasus and subgenera Prunophora or Amygdalus is greater than that of subgenus Cerasus (Ding, 1997; Mizutani et al., 1985). Thus, our results support a classification system that separates bush cherry and rock cherry into either subgenus Lithocerasus or subgenus Prunophora. 
The STATUS AND Relationship OF $P$. tomentosa AND $P$. TRILOBA. The species $P$. tomentosa and $P$. triloba are morphologically similar and are mainly distinguished by fruit morphology. The fruit of $P$. triloba is larger and dry at maturity, whereas the fruit of $P$. tomentosa is smaller and remains fleshy. However, it is difficult to distinguish the two species without flowers or fruit, and few studies have investigated their phylogenetic relationship. The topology of the present study agrees with the species' morphological similarity, since $P$. tomentosa and $P$. triloba were grouped together and formed a sister group to subgenus Prunophora. Previously, RAPD analysis (Shimada et al., 2001) placed the two species in subgenus Amygdalus; however, isozyme analysis grouped the species together as a separate clade that was closer to members of subgenus Prunophora than to those of subgenus Cerasus (Mowrey and Werner, 1990). Further, according to the analysis of nrITS sequences and plastid markers (Chin et al., 2014), $P$. tomentosa and $P$. triloba are grouped together and are more closely related to P. glandulosa (subgenus Lithocerasus) and subgenus Prunophora than to subgenus Amygdalus or subgenus Cerasus. Our findings support the conclusions drawn from the analysis of isozymes, nrITS sequences, and plastid markers.

Traditionally, $P$. triloba has been placed in subgenus Amygdalus; however, this classification has been questioned. For example, Zhao (1996) suggested that $P$. triloba be placed in subgenus Cerasus, along with $P$. tomentosa, based on morphology. In addition, although $P$. triloba can be used as a rootstock for plum, apricot, and peach, it causes dwarfing in peach (Ding, 1997), a phenomenon that might be explained by genetic distance, since $P$. triloba is more closely related to subgenus Prunophora (plum and apricot) than to subgenus Amygdalus (peach, nectarine, and almond). Our results also support this point of view.

Meanwhile, $P$. tomentosa cannot be used directly as a rootstock for sweet cherry, owing to the incompatibility of the two species, although using $P$. tomentosa as a rootstock and Fuli $(P$. salicina) as an interstock produces sweet cherries that grow well and fruit earlier. Grafting compatibility also suggests that $P$. tomentosa is more closely related to subgenus Prunophora than to subgenus Cerasus, since a hybrid rootstock for peach was derived from a cross between P. tomentosa and Prunus cerasifera (Warner, 1998). The interspecific hybridization of P. tomentosa and P. salicina (Zhang and Gu, 2015) also supports the conclusion that $P$. tomentosa is more closely related to subgenus Prunophora than to subgenus Cerasus. Therefore, the results of the present study suggest that $P$. triloba and $P$. tomentosa should be assigned to the same group, either in subgenus Lithocerasus or subgenus Prunophora, rather than in subgenus Amygdalus.

Implications for PrUnUS ROOTSTOCK BREeding. The genetic resources of Chinese Prunus species have made important contributions to global fruit production, either by direct planting or as breeding material. In addition, Chinese Prunus species may also be useful as a source of genetic variation for breeding Prunus rootstocks, especially since interspecific crosses in the genus are usually feasible and efficient (in terms of selection pressure). Such interspecific crosses permit the introgression of beneficial genes for tolerance to drought and cold and resistance to pests and disease, from wild species to cultivated species, which can result in progeny that can be cultivated over a wide range of climates or have a wide range of compatibility with other cultivars.
To identify suitable rootstocks for stone fruits, grafting experiments have typically focused on more primitive species from China, such as $P$. pseudocerasus, $P$. canescens, $P$. tomentosa, $P$. humilis, $P$. japonica, and $P$. triloba, which are characterized by their cold resistance, dwarfing, and early fruiting. Further, distant hybridization within Prunus species has been widely applied as the preferred strategy for fruit production and has yielded a number of cultivars. For example, 'Colt' $(P$. avium $\times$ P. pseudocerasus $)$ and 'Gisela 5' and 'Gisela 6' $(P$. cerasus $\times P$. canescens $)$ have been important rootstocks for sweet cherry (Bielicki and Rozpara, 2010), whereas a hybrid rootstock from a cross between $P$. tomentosa and $P$. cerasifera is used for peach (Warner, 1998), and an interspecific hybrid of $P$. tomentosa and $P$. salicina exhibited dwarfing, large fruit, and cold resistance (Zhang and $\mathrm{Gu}, 2015$ ). However, an improved understanding of the genetics of Prunus species is fundamental to the development of new breeding programs, and the close relationships identified in the present study will improve Prunus breeding programs by helping breeders choose parental combinations and allow the combination of some major characteristics from wild species.

\section{Conclusions}

The findings of the present study clarify the relationships and genetic diversity of 10 Prunus species from China. Although members of subgenus Lithocerasus are morphologically similar to members of subgenus Cerasus, the two groups are genetically distinct, and our analysis also indicated that the four examined species of subgenus Lithocerasus (i.e., $P$. humilis, $P$. japonica, $P$. glandulosa, and $P$. tomentosa) were more closely related to members of subgenus Prunophora than to those of subgenus Amygdalus or subgenus Cerasus. Furthermore, $P$. triloba was genetically distant from members of subgenus Amygdalus but was closely related to $P$. tomentosa. Therefore, we suggest that $P$. triloba be grouped with $P$. tomentosa and placed in either subgenus Lithocerasus or subgenus Prunophora. The results of our molecular analysis can also be used to direct breeding programs for Prunus rootstocks.

\section{Literature Cited}

Aranzana, M.J., J. Garcia-Mas, J. Carbo, and P. Arus. 2002. Development and variability analysis of microsatellite markers in peach. Plant Breed. 121:87-92.

Badenes, M.L. and D.D.E. Parfitt. 1995. Phylogenetic relationships of cultivated Prunus species from an analysis of chloroplast DNA variation. Theor. Appl. Genet. 90:1035-1041.

Bielicki, P. and E. Rozpara. 2010. Growth and yield of 'Kordia' sweet cherry trees with various rootstock and interstem combinations. J. Fruit Ornamental Plant Res. 18:45-50.

Bortiri, E., B. Vanden Heuvel, and D. Potter. 2006. Phylogenetic analysis of morphology in Prunus reveals extensive homoplasy. Plant Syst. Evol. 259:53-71.

Cantini, C., A.F. Iezzoni, W.F. Lamboy, M. Bortizki, and D. Struss. 2001. DNA fingerprinting of tetraploid cherry germplasm using simple sequence repeats. J. Amer. Soc. Hort. Sci. 126:205-209.

Chin, S.W., J. Shaw, R. Haberle, J. Wen, and D. Potter. 2014. Diversification of almonds, peaches, plums and cherries-Molecular systematics and biogeographic history of Prunus (Rosaceae). Mol. Phylogenet. Evol. 76:34-38.

Cipriani, G., G. Lot, W.G. Huang, M.T. Marrazzo, E. Peterlunger, and R. Testolin. 1999. AC/GT and AG/CT microsatellite repeats in peach [Prunus persica (L) Batsch]: Isolation, characterisation and crossspecies amplification in Prunus. Theor. Appl. Genet. 99:65-72. 
Decroocq, V., M.G. Fav, L. Hagen, L. Bordenave, and S. Decroocq. 2003. Development and transferability of apricot and grape EST microsatellite markers across taxa. Theor. Appl. Genet. 106:912922.

Ding, Z.X. 1997. A review on dwarfing rootstocks of deciduous fruit and their dwarfing effect in China (in Chinese). J. Sichuan Agr. Univ. 15:358-364.

Dirlewanger, E., P. Cosson, M. Tavaud, M.J. Aranzana, C. Poizat, A. Zanetto, P. Arus, and F. Laigret. 2002. Development of microsatellite markers in peach [Prunus persica (L.) Batsch.] and their use in genetic diversity analysis in peach and sweet cherry (Prunus avium L.). Theor. Appl. Genet. 105:127-138.

Dosba, F., R. Bernhard, and A. Zanetto. 1994. Importance des ressources génétiques des Prunus. C. R. Acad. Agr. Fr. 80:45-57.

Doyle, J.J. and J.L. Doyle. 1990. Isolation of plant DNA from fresh tissue. Focus 12:13-15.

Fan, S.Y. 1999. The experiment of affect scion of Prunus japonica Thunb for stock of Prunus armeniaca L. (in Chinese). Hereditas 21:43-44.

Felipe, A.J. 2009. 'Felinem', 'Garnem', and 'Monegro' almond $\times$ peach hybrid rootstocks. HortScience 44:196-197.

Garley, B. 1980. The sand cherry: Its origin, improvement and nomenclature. Fruit Var. J. 34:13-17.

Ingram, C. 1948. Ornamental cherries. Country Life, London, UK.

Jones, D.F. 1928. Burbank's results with plums. J. Hered. 19:359-372.

Kataoka, I., A. Sugiura, and T. Tomana. 1988. Interspecific hybridization between Microcerasus and other Prunus species. J. Jpn. Soc. Hort. Sci. 56:398-407.

Mizutani, F., M. Yamada, and T. Taniguchi. 1985. Dwarfing effect of $P$. japonica and $P$. tomentosa rootstocks on 'Ohkubo' peach trees. Engei Gakkai Zasshi 54:327-335.

Mowrey, B.D. and D.J. Werner. 1990. Phylogenetic relationships among species of Prunus as inferred by isozyme markers. Theor. Appl. Genet. 80:129-133.

Olden, E.J. and N. Nybom. 1968. On the origin of Prunus cerasus L. Hereditas 59:327-345.

Powell, W., M. Morgante, C. Andre, M. Hanafey, J. Vogel, S. Tingley, and A. Rafalski. 1996. The comparison of RFLP, RAPD, AFLP and SSR (microsatellite) markers for germplasm analysis. Mol. Breed. 2:225-238.

Rehder, A. (ed.). 1990. Manual of cultivated trees and shrubs hardy in North America. Dioscorides Press, Portland, OR.
Sangtae, L. and J. Wen. 2001. A phylogenetic analysis of Prunus and the Amygdaloideae (Rosaceae) using ITS sequences of nuclear ribosomal DNA. Amer. J. Bot. 88:150-160.

Shimada, T., H. Hayama, K. Nishimura, M. Yamaguchi, and M. Yoshida. 2001. The genetic diversities of 4 species of subgenus Lithocerasus (Prunus, Rosaceae) revealed by RAPD analysis. Euphytica 117:85-90.

Shoferistov, E.P. 1989. Use of distant hybridization in breeding nectarine. Otdalennaya gibridizatsiya I ee rol, v intensifikatsii sadovodstva 18:76-81.

Sosinski, B., M. Gannavarapu, L.D. Hager, L.E. Beck, G.J. King, C.D. Ryder, S. Rajapakse, W.V. Baird, R.E. Ballard, and A.G. Abbott. 2000. Characterization of microsatellite markers in peach [Prunus persica (L.) Batsch.]. Theor. Appl. Genet. 101:421-428.

Struss, D., R. Ahmad, and S.M. Sourthwick. 2003. Analysis of sweet cherry (Prunus avium L.) cultivars using SSR and AFLP markers. J. Amer. Soc. Hort. Sci. 128:904-909.

Swofford, D.L. 1998. PAUP*: Phylogenetic analysis using parsimony, version 4. 0b2. Illinois Natural History Survey, Champaign, IL.

Testolin, R., T. Marrazzo, G. Cipriani, R. Quarta, I. Verde, M. Dettori, M. Pancaldi, and S. Sansavini. 2000. Microsatellite DNA in peach [Prunus persica (L.) Batsch] and its use in fingerprinting and testing the genetic origin of cultivars. Genome 43:512-520.

Uematsu, C., T. Sasakuma, and Y. Ogihara. 1991. Phylogenetic relationships in the stone fruit group of Prunus as revealed by restriction fragment analysis of chloroplast DNA. Jpn. J. Genet. 66:59-69.

Warner, G. 1998. Russian stone fruit roootstocks show promise. Good Fruit Grower 49(10):11.

Watkins, R. 1976. Cherry, plum, peach, apricot and almond, p. 242247. In: N.W. Simmons (ed.). Evolution of crop plants. Longman, London, UK.

Yü, T.T. and C.L. Li. 1986. Cerasus, p. 1-133. In: T.T. Yü (ed.). Flora reipublicae popularis sinicae 38. Science Press, Beijing, China.

Zhang, Q.J. and D.J. Gu. 2015. Development of a new hybrid between Prunus tomentosa Thunb. and Prunus salicina Lindl. HortScience 50:517-519.

Zhang, Q.J., G.J. Yan, H.Y. Dai, X.Z. Zhang, C.M. Li, and Z.H. Zhang. 2008. Characterization of tomentosa cherry (P. tomentosa Thunb.) genotypes using SSR markers and morphological traits. Sci. Hort. 118:39-47.

Zhao, Y.Z. 1996. On systematic position of Cerasus triloba (in Chinese). J. Inner Mongolia Univ. 27:70-71. 